\begin{tabular}{|c|c|c|c|c|c|c|}
\hline \multirow{4}{*}{ Impact Factor: } & ISRA (India) & $=3.117$ & SIS (USA) & $=0.912$ & ICV (Poland) & $=6.630$ \\
\hline & ISI (Dubai, UAE & $=0.829$ & РИНЦ (Russia) & 1) $=\mathbf{0 . 1 5 6}$ & PIF (India) & $=1.940$ \\
\hline & GIF (Australia) & $=0.564$ & ESJI (KZ) & $=8.716$ & IBI (India) & $=4.260$ \\
\hline & JIF & $=1.500$ & SJIF (Morocco & $=5.667$ & OAJI (USA) & $=0.350$ \\
\hline
\end{tabular}

\begin{tabular}{|c|c|}
\hline $\begin{array}{l}\text { SOI: } \frac{1.1 / \mathrm{TA}}{} \\
\text { International Sc } \\
\text { Theoretical } \boldsymbol{\&} \mathbf{A}\end{array}$ & $\begin{array}{l}\frac{S}{\text { DOI: }} \text { 10.15863/TAS } \\
\text { ientific Journal } \\
\text { pplied Science }\end{array}$ \\
\hline p-ISSN: 2308-4944 (print) & e-ISSN: 2409-0085 (online) \\
\hline Year: 2019 Issue: 03 & Volume: 71 \\
\hline Published: 30.03 .2019 & http://T-Science.org \\
\hline
\end{tabular}

SECTION 21. Pedagogy. Psychology. Innovations in the field of education.
QR - Issue

QR - Article
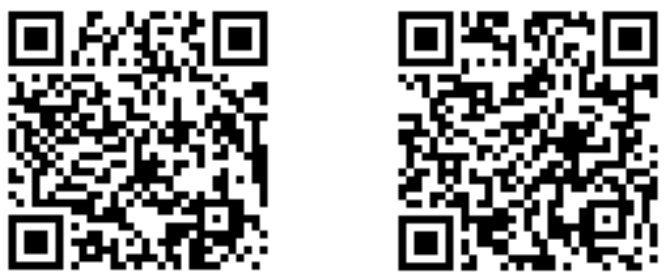

T.A. Konurbayev

Candidate of psychological Sciences, Kyrgyz state university named after I.Arabayeva

S.M. Ussenova

Master of Psychology

Taraz State University named after Dulati

\title{
TEACHER'S TRAINING IN SENSITIVE SELF-REGULATION TECHNIQUES AS A FACTOR IN THE CORRECTION OF HIS EMOTIONAL STATE
}

Abstract: The article analyzes the task of transition to a model of secondary education, focused on training future citizens, capable of independent creative search, enterprising professionals with high moral goals, selfsufficient and self-actualized, psychologically healthy personalities.

Key words: psycho-hygienic measures, psychoprophylaxis, conflict.

Language: Russian English

Citation: Konurbayev, T. A., \& Ussenova, S. M. (2019). Teacher's training in sensitive self-regulation techniques as a factor in the correction of his emotional state. ISJ Theoretical \& Applied Science, 03 (71), 564-572.

Soi: http://s-o-i.org/1.1/TAS-03-71-56 Doi: crostef https://dx.doi.org/10.15863/TAS.2019.03.71.56

\section{ОБУЧЕНИЕ УЧИТЕЛЯ СЕНСИТИВНЫМ ПРИЕМАМ САМОРЕГУЛЯЦИИ КАК ФАКТОР КОРРЕКЦИИ ЕГО ЭМОЦИОНАЛЬНОГО СОСТОЯНИЯ}

Аннотация: В статье анализируется задача перехода на модель среднего обучения, ориентированного на подготовку будущих граждан, способных к самостоятельному творческому поиску, предприимчивых профессионалов с высокими нравственными целями, самодостаточными и самоактуализированными, психологически здоровыми личностями.

Ключевые слова: психогигиенические мероприятия , психопрофилактика, конфликт.

\section{Introduction}

Последнее десятилетие прошлого века и настоящее время знаменуются повышенным вниманием к проблемам психопрофилактики, связанным с ростом числа заболеваний, в генезе которых большое значение имеет психоэмоциональный фактор. Причины роста числа этих заболеваний широко обсуждаются в специальной и общей печати и связываются с проблемой стресса и адаптации человека к быстро меняющимся условиям внешней среды (Мягер, 1983; Александровский, 1992, 1993; Глоточкин, 1993; Вассеман, Боков, 1995; Вассерман, Березин, 1997; Степанова, 2003; Дубровина, 2004; С.М.Джакупов, 2005 и др. )

Materials and Methods
Понятие психопрофилактики тесно связано с понятием психогигиены. В свою очередь, психогигиена настолько связана с психопрофилактикой, что в некоторых случаях почти невозможно разделить их объекты и предметы изучения. Общие задачи психогигиены и психопрофилактики имеют тем не менее некоторые различия, так как психогигиена есть отрасль общей гигиены, а психопрофилактика психиатрическая дисциплина. Задачи психогигиены - сохранение психического здоровья, изучение факторов, положительно или отрицательно влияющих на состояние психического здоровья, создание условий, способствующих гармоничному развитию личности, разработка психогигиенических нормативов и тому подобное. Психопрофилактика, будучи составной частью 


\begin{tabular}{|c|c|c|c|c|c|c|}
\hline \multirow{4}{*}{ Impact Factor: } & ISRA (India) & $=3.117$ & SIS (USA) & $=0.912$ & ICV (Poland) & $=6.630$ \\
\hline & ISI (Dubai, UAE & $=0.829$ & РИНЦ (Russia & $=0.156$ & PIF (India) & $=1.940$ \\
\hline & GIF (Australia) & $=0.564$ & ESJI (KZ) & $=8.716$ & IBI (India) & $=4.260$ \\
\hline & JIF & $=1.500$ & SJIF (Morocco & $=5.667$ & OAJI (USA) & $=0.350$ \\
\hline
\end{tabular}

конкретной клинической дисциплины, имеет следующие задачи: предупреждение психических заболеваний; предупреждение перехода психических заболеваний в хронические формы; социально - трудовая реабилитация больных. Психогигиена и психопрофилактика решают задачи сохранения психического здоровья населения и предупреждения психических заболеваний.Они являются сторонами одного процесса, где задача психопрофилактики - не допустить возникновения психического заболевания, а задача психогигиены - создать условия, обеспечивающие оптимальное психического состояние (Голлай, 1993).

Психогигиенические мероприятия имеют профилактическое значение не только в отношении психогенных и различных соматических заболеваний, но также и при организации труда, поскольку система правильных отношений внутри коллектива сама уже имеет психогигиеническое значение. Нормальный ритм учебного процесса, удовлетворенность результатами своего труда, постоянное повышение профессионального уровня - важнейшие факторы, позволяющие человеку чувствовать себя комфортно, а это уже профилактика дистресса и психогенных заболеваний (Матвеев, 1989; Карвасарский, 1998). Именно этот аспект психогигиены и психопрофилактики интересовал нас в первую очередь.

По мнению А.Д.Глоточкина (1993), А.В.Адова (1996), Л.М.Александровой (1996), Т.М.Артишевской (1996), Т.Д.Барышевой (1996), П.Н.Виноградова (1997), Д.Ж.Марковича (2001), А.В.Басова (2002), 3.Б.Маданиевой (2002), М.А.Степановой (2003), И.В.Дубровиной (2004) сегодня, как ни в какое иное время, с особой четкостью видится необходимость придания всей школьной практике психопрофилактического направления. Для предупреждения психических заболеваний, для сохранения психического здоровья учащихся и учителей как самой приоритетной социальной ценности нельзя жалеть ни усилий, ни средств.

При разработке профилактических программ в школе мы опирались на принципы первичной психопрофилактики (Лакосина, Ушаков, 1976; Матвеев, 1989; Карвасарский, 1998).

Как известно,

первичная психопрофилактика складывается из общих мероприятий, направленных на повышение уровня психического здоровья населения, и специфической части, которая включает раннюю диагностику (первичный уровень), сокращение числа патологических нарушений (вторичный уровень) и реабилитацию (третий уровень).

В первичной психопрофилактике выделяют психическую профилактику, которая направлена на изучение психического воздействия на человека, свойств его психики и возможностей предупреждения психогенных и психосоматических болезней. Все мероприятия, относящиеся к психической профилактике, направлены на повышение степени сопротивляемости психики вредным воздействиям и на предупреждение любых заболеваний, в генезе которых существенную роль играет эмоционально - аффективное перенапряжение (Лакосина, Ушаков, 1976; Вассерман, Боков, 1995; Воробьев, Коновалова, 1995; Матвеева, Львова, 1997; Карвасарский, 1998; Спиваковская, 1999; Казин, Федоров, Панина, Заруба, 2001; Гребельников, 2002).

При предупреждении расстройства психической деятельности, то есть в комплексе психопрофилактических мер, следует учитывать как факторы окружающей среды, так и этиологические и патогенные факторы, существующие в человеке, обусловленные его конституцией и преморбидными личностными особенностями. Здесь нужно иметь в виду три аспекта: 1. личностный; 2. интерперсонального взаимодействия; 3 . ситуационный - в их взаимосвязи.

Кроме того, при разработке психопрофилактических мер нами учитывались, а затем, при их осуществлении, использовались защитные силы самого организма, сохранные стороны психики, которые следует стимулировать, усиливая сопротивление организма и личности к болезни и компенсируя ее последствия (Выготский, 1984).

В процессе профессиональной деятельности учителя на него влияет ряд факторов, неблагоприятно сказывающихся на его здоровье. Большая психоэмоциональная нагрузка неблагоприятно сказывается не его здоровье, ведет к перенапряжению нервной системы. Кроме того, сегодня учителя испытывают страх перед новым, скованность своим прежним опытом и неспособность действовать «здесь и теперь», неумение отступать от принципов, стереотипов. Именно эта боязнь рождает страх, неуверенность в себе, учитель начинает проявлять растерянность, разочарование, раздражительность и негативизм. Учителю в его педагогической деятельности необходимы навыки саморегуляции, самообладания, рациональных способов общения и адекватными приемами наблюдательности.

Казалось бы, что педагогические коллективы состоят из людей, наиболее подготовленных к сотрудничеству, совместному творчеству и взаимопониманию. Успешное сотрудничество в школьных коллективах предполагает готовность людей к пониманию друг друга, к саморегуляции своих эмоций, способности целенаправленно и сознательно строить отношения в ходе 


\begin{tabular}{|c|c|c|c|c|c|c|}
\hline \multirow{4}{*}{ Impact Factor: } & ISRA (India) & $=3.117$ & SIS (USA) & $=0.912$ & ICV (Poland) & $=6.630$ \\
\hline & ISI (Dubai, UAE & $=0.829$ & РИНЦ (Russia & $=0.156$ & PIF (India) & $=1.940$ \\
\hline & GIF (Australia) & $=0.564$ & ESJI (KZ) & $=8.716$ & IBI (India) & $=4.260$ \\
\hline & JIF & $=1.500$ & SJIF (Morocco & $=5.667$ & OAJI (USA) & $=0.350$ \\
\hline
\end{tabular}

совместной деятельности, изменять свое поведение на основе знания целей коллектива, учащихся, других людей и особенностей своей личности, перестраивать свою деятельность в соответствии с коллективной значимостью, во благо здорового подрастающего поколения.

Известно, что педагогические коллективы в основном женские. А повышенная эмоциональная возбудимость женщин в обстановке напряженной психической деятельности осложняют взаимоотношения. Кроме того, внушаемость женщин влияет на состояние настроения в коллективе. Динамическое заражение настроением друг друга, соединенное нередко с низкой культурой чувств, обнаруживается в резких и трудно прогнозируемых проявлениях: крик, слезы, бурные выражения радости и гнева.

Постоянное пребывание в профессиональной роли «учить других» формируют у учителя устойчивую установку «я всегда прав, дети виноваты». Учитель перестает сомневаться в правильности своих поступков и высказываний. В речи появляется директивный менторский тон, категоричные оценочные суждения в адрес коллег, учащихся и родителей. Подобное поведение нередко служит причиной конфликтов.

К сожалению, в некоторых школах конфликтные отношения не редкость. Их напряженный характер, борьба чрезвычайно мешают решению воспитательных задач, нарушают нормальную деятельность учителя. Наиболее типичными возбудителями конфликтов в школе можно назвать следующее:

- плохая организация труда (отсутствие четкости и определенности в работу учителя, неудачное расписание, перегрузки общественной работой и заданиями рутинного, побочного характера).

- Неудовлетворенность

взаимоотношениями между учителями и администрацией (несправедливость руководителей, грубость, неправильные действия администрации, руководителей, некомпетентность . сложные семейные материально - бытовые условия жизни педагога).

- взаимное непонимание учителей (обидчивость, мнительность, несоответствие уровня притязаний статусу в педагогическом коллективе, бестактность в замечаниях, в высказываниях в адрес друг друга и т.п.).

Конфликт в любом случае дезорганизует людей и является сильным отрицательным воздействием. Профессиональная роль заметно влияет на личность. Предъявляя к человеку определенный набор требований, она тем самым направленно преобразует весь его облик.
Ежедневные на протяжении многих лет решения типовых задач не только совершенствуют профессиональные знания, но и формируют профессиональные привычки, определенный склад мышления и стиль общения.

У учителей обладающих определенной властью над учащимися, отмечаются специфические черты в поведении, существенно влияющие на стиль и характер взаимодействия с людьми. С годами учитель все в большей мере склонен оценивать поступки всех окружающих в моральных категориях. Возникновение чувства превосходства и даже высокомерия ослабляет его способность к самокритике. Наблюдается непринятие шуток в свой адрес. Подобная нечувствительность закрывает пути интеллектуального развития. Приверженность к правилам и распорядкам способствует появлению формализма и сухости в личных взаимоотношениях и в отношениях с учащимися. Критический фактор личной деформации хроническая перегрузка. Из-за нее труд приносит неудовлетворение и неблагоприятно сказывается на отношениях с окружающими. Перегрузка приводит к резкому сужению круга общения и качественному его изменению. Вечно занятые, они не читают, не смотрят фильмы, не ходят в театр, постепенно теряя интерес к событиям в культурной жизни, интеллектуально не развиваются. Перегрузка ведет к повышению раздражительности, что тоже способствует сужению интересов, ограниченности взглядов и суждений.

В целях улучшения эффективности педагогического труда учителя и повышения познавательной активности у учащихся нами разработана комплексная методика коррекции эмоциональной сенситивности учителя, которая состоит из 12 занятий, включающих в себя лекционный материал, рисуночной и тестовой диагностики, тренинга развития эмоциональной сенситивности и поведенческой саморегуляции.

Необходимость создания программы тренинга обусловлена современными требованиями к повышению эмоциональной сенситивности педагогов в связи с переходом на 12-летнее общеобразовательное обучение. Отсюда в педагогической деятельности учителю необходимы навыки саморегуляции, рациональных способов общения и развитой эмоциональной сенситивности. Нужна практическая коррекционная работа по формированию новых установок и способов поведения для стабилизации психического здоровья учащихся 12-летего образования.

Происходящие сегодня глобальные изменения в образовательном процессе затрагивают все стороны жизни учителей. Им 


\begin{tabular}{|c|c|c|c|c|c|c|}
\hline \multirow{4}{*}{ Impact Factor: } & ISRA (India) & $=3.117$ & SIS (USA) & $=0.912$ & ICV (Poland) & $=6.630$ \\
\hline & ISI (Dubai, UAE & $=0.829$ & РИНЦ (Russia & $=0.156$ & PIF (India) & $=1.940$ \\
\hline & GIF (Australia) & $=0.564$ & ESJI (KZ) & $=8.716$ & IBI (India) & $=4.260$ \\
\hline & JIF & $=1.500$ & SJIF (Morocco & $=5.667$ & OAJI (USA) & $=0.350$ \\
\hline
\end{tabular}

необходима психологическая и социальная адаптация к новой реальности.

В психологической науке теория и практика тренингов разработана достаточно глубоко. Существует множество подходов к определению понятия «тренинг», которое объясняется как «группа методов развития способностей к обучению и овладению любым сложным видом деятельности» (Ю.Н.Емельянов), «средство воздействия, направленное на развитие знаний, социальных установок, умений и опыта в области межличностного воздействия»(Л.А.Петровская), «активное групповое обучение навыкам общения в жизни и обществе» (Н.В.Цзен, Ю.В.Пахомов), «многофункциональный метод преднамеренных изменений психологических феноменов человека, группы и организации с целью гармонизации профессионального и личностного бытия человека» (Н.П.Аникеева).

Американский психолог Г.Смит, раскрывший теорию тренинга сенситивности, считает, что ответ на вопрос, какую точку зрения стоит принять, зависит от того, что мы хотим: отбирать сенситивных людей или же тренировать их. При отборе должно быть отдано предпочтение взгляду на сенситивность как на общую способность, для тренинга больше подходит многокомпонентная теория, так как именно она дает ключ к тому, с чего начинать тренинг, для чего тренировать, как это делать, и добавим от себя, - что тренировать.

Термин «сенситивность»в данном контексте понимается как способность предсказывать мысли, чувства и поведение другого человека, как способность воспринимать, понимать, запоминать и структурировать социально-психологические характеристики других людей или группы на основании этого прогнозировать их поведение и деятельность.

Г.Смит (Smith Н., 1973) выделил четыре компонента сенситивности. Основанием для такой классификации послужил анализ теорий и практики специалистов в области сенситивного тренинга, а также собственный опыт автора.

Выделяет четыре вида сенситивности:

- наблюдательная

сенситивность

(способность наблюдать, т.е. видеть и слышать другого человека и запоминать при этом, как он выглядел и что говорил),

- теоретическая

сенситивность

(способность применять различные теории для интерпретации и прогнозирования поведения, чувств и мыслей других людей),

- номотетическая

сенситивность

(способность понимать типичного представителя той или иной социальной группы и использовать это понимание для прогнозирования поведения людей, принадлежащих к даной группе),
- идеографическая (способность понимать своеобразие данного человека).

Итак, педагогическая наблюдательная сенситивность - способность наблюдать (видеть и слышать ученика и одновременно запоминать, как он выглядел, что и говорил, и главное, как говорил) будет являться фактором эмоционального комфорта преподавателя современной школы и ее воспитанников.

Многие авторы рассматривают педагогическую наблюдательную сенситивность как целостное, общее свойство, как способность предсказывать (прогнозировать) чувства, мысли и поведение другого человека. Другие авторы отдают предпочтение многокомпонентной теории.

В работе А.К.Марковой: «Профессиональные позиции - это устойчивые системы отношений учителей (к ученику, к себе, к коллегам), определяющие его поведение. Профессиональная позиция тесно связана с сенситивностью учителя, с осознанием его труда».

Е.Е.Сапогова утверждает, что через глубину сформированности положений, составляющих структуру профессиональной сенситивности педагога, определяется как минимум две профессиональные

конкурентноспособность

неконкурентоспособность. И вводит формулировку - «продуктивные Профессиональные позиции» и «непродуктивные Профессиональные позиции».

В педагогической практике особый интерес представляет эмоциональная наблюдательная сенситивность. При этом наблюдению подлежат:

- речевые акты, их содержание, последовательность, интенсивность, направленность, частота, продолжительность, уровень экспрессии, особенности лексики, грамматики, фонетики, интонации и голосовых качеств говорящего, рече моторная синхронизация, графические проявления (почерк, рисунок);

- выразительные движения (лица, тела);

- перемещения и позы людей, дистанция между ними, скорость и направление движений, аранжировка в межличностном пространстве;

- тактильные воздействия (касания, поддерживающие жесты, толчки), передача и отнятие предметов, удержание;

- запахи и локализация их источников;

- эмоциональные проявления (страх, вина, робость, гнев, радость, раздражение и т.п.),

- сочетание перечисленных действий, признаков и характеристик.

К эмоциональной наблюдательной сенситивности относится самонаблюдение 


\begin{tabular}{|c|c|c|c|c|c|c|}
\hline \multirow{4}{*}{ Impact Factor: } & ISRA (India) & $=3.117$ & SIS (USA) & $=0.912$ & ICV (Poland) & $=6.630$ \\
\hline & ISI (Dubai, UAE & $=0.829$ & РИНЦ (Russia & $=0.156$ & PIF (India) & $=1.940$ \\
\hline & GIF (Australia) & $=0.564$ & ESJI (KZ) & $=8.716$ & IBI (India) & $=4.260$ \\
\hline & JIF & $=1.500$ & SJIF (Morocco & $=5.667$ & OAJI (USA) & $=0.350$ \\
\hline
\end{tabular}

(интроспекция). Г.Смит рассматривает наблюдение в этом контексте, не как пассивный акт запечатления, замечая при этом, что все, что мы видим и слышим, проходит сквозь призму нашего сознания, и мы получаем в результате то, что хотим получить. Влияние установок, стереотипов, опыта приводит к субъективным искажениям образа «Я» и других людей. Желания, предположения, привычные способы восприятия могут «программировать» наблюдение, фокусируя внимание на ограниченных фрагментах поведения человека. Поэтому развитие навыков отграничения того, что мы слышим и видим, от чувств, эмоций и мыслей по поводу этого относится к важным задачам тренинга эмоциональной сенситивности.

Таким образом, эмоциональная сенситивность может рассматриваться как способность, обеспечивающая:

1.отражение и понимание;

2.запоминание и структурирование социально-психологических характеристик человека и группы и прогнозировать их поведение и деятельность.

Развитие эмоциональной сенситивности может осуществляться в процессе осознания человеком её структуры и индивидуальных особенностей протекания социальноперцептивных процессов путем включения в проблемные ситуации, требующие актуализации.

Возникновение психологического тренинга как новой формы взаимодействия психолога с людьми, нуждающимися в психологической помощи, и этих людей между собой, теснейшим образом связано с развитием групповой психотерапии и психокоррекцией. Вместе с тем, мы считаем необходимым, обозначить различие между этими понятиями.

Под психотерапией в настоящее время как принято понимать комплексное лечебное вербальное и невербальное воздействие на эмоции, суждения, самосознание человека при многих психических нервных и психосоматических заболеваниях. Условно различают клинически ориентированную психотерапию, направленную преимущественно на смягчение или ликвидацию имеющейся симптоматики, и личностно - ориентированную психотерапию, которая стремиться помочь человеку изменить свое отношение к социальному окружению и к собственной личности [1;2].

Психологическая коррекция определяется как направленное психологическое воздействие на те или иные психологические структуры с целью обеспечения полноценного развития и функционирования личности [3]. Групповую психологическую коррекцию обычно рассматривают не только (и не столько), как метод, применяемый в медицине, но и в качестве направлений деятельности практического психолога (не обязательно врача психотерапевта).

Групповая психотерапия гораздо старше психологического тренинга - ее возникновение в собственном смысле слова относится к 1904 1905гг., связывая этот момент с врачебной деятельностью И.В.Вяземского (Россия) и Дж.Прэтта (США), а появлением термина «групповая психотерапия» мы обязаны Дж. Морено, предложившему его в 1932 году. Между тем временем возникновения психологического тренинга принято считать только 50-е годы, когда М.Форверг разработал новый метод, основой которого были ролевые игры с элементами драматизации и который был назван социально психологическим тренингом - СПТ.

На основании большой экспериментальной исследовательской работы Форверг сделал вывод об эффективном влиянии СПТ на повышение интерперсональной компетентности за счет интериризации измененных установок личности и их переноса на их профессиональную деятельность.

В «Психологическом словаре» (1990) социально - психологический тренинг определяется как «область практической психологии, ориентированной на использование активных методов групповой психологической работы с целью развития компетентности общения». Групповой психологический тренинг не сводится только к социально психологическому. Область его применения значительно шире, чем у последнего, и отнюдь не ограничивается развитием навыков эффективного общения и повышением коммуникативной компетентности.

Один из ведущих специалистов по тренингам Ю.М.Емельянов отмечает: «При этом термин «тренинг», по нашему мнению, в структуре русской психологической речи должен использоваться не для обозначения методов обучения, а для обозначения методов развития способностей к обучению или овладению любым сложным видам деятельности в частности общения» [5].

Так, известный специалист в области нейролингвистического программирования и акмеологии А.П.Ситников, дает такое определение тренинга: «Тренинги (обучающие игры) являются синтетической антропотехнической, сочетающей в себе учебную и игровую деятельность, проходящей в условиях моделирования различных игровых ситуаций...» [6].

А.П.Ситников, например, понимает программно - целевую направленность тренинга как системы обучения и подготовки профессиональных кадров на воссоздание 


\begin{tabular}{|c|c|c|c|c|c|c|}
\hline \multirow{4}{*}{ Impact Factor: } & ISRA (India) & $=3.117$ & SIS (USA) & $=0.912$ & ICV (Poland) & $=6.630$ \\
\hline & ISI (Dubai, UAE & $=0.829$ & РИНЦ (Russia & $=0.156$ & PIF (India) & $=1.940$ \\
\hline & GIF (Australia) & $=0.564$ & ESJI (KZ) & $=8.716$ & IBI (India) & $=4.260$ \\
\hline & JIF & $=1.500$ & SJIF (Morocco & $=5.667$ & OAJI (USA) & $=0.350$ \\
\hline
\end{tabular}

целостного феномена профессионального мастерства, характерного для конкретного вида профессиональной деятельности» [4].

Отработана характеристика общих принципов тренингов ой работы: активности, исследовательской позиции, осознания поведения, партнерского общения. Определены все структурные составляющие программ тренинга, требования к его организации и проведению, к участникам, тренеру группы.

В структуру тренинга обычно вводятся поведенческие компоненты (отработка практических навыков), рефлексивные (развитие рефлексирования как психологического образования), коммуникативные (понимание и отработка навыков слушания, коммуникации), релаксационные (развитие навыков саморегуляции и релаксации) и другие составляющие, внесение которых оптимально на данном уровне.

Тренинг является методом раскрытия и совершенствования человеческого потенциала вербального и невербального самовыражения. Этот метод основан на актуализации своих чувств и эмоций. Главным является реализация индивидуального подхода, создание условий для личностного роста.

Разработка и применение тренинга. Направленного на повышение восприимчивости к групповым процессам, компетентности в сфере общения, рефлексирование собственных социально - перспективных возможностей, имеют в науке собственную историю.

Впервые К.Роджерс подробно описал закономерные процессы, происходящие в группе людей, не связанных предметной задачей.

Огромное значение для развития групповой психотерапии имела концепция психодрамы разработанная Дж. Морено. В основе психотерапевтического эффекта психодрамы лежит катарсис (очищение), источником которого, по Дж. Морено, является способность к адекватной реакции на внезапно возникшие обстоятельства. И задача ее заключается в естественном выражении «Я», что позволяет снимать перенапряжение.

Особым направлением в групповой психотерапии является объединение групповых механизмов с принципами трансактного анализа, разработанного Э.Берном и его последователями.

Ф.Ридль и С.Славсон, применяя групповой психоанализ, использовали катарсис, тем самым открывая дорогу более теплым отношениям, снимая беспокойство, чувство вины и страха.

Важным направлением групповых методов в психологии является распространение различных форм активного социального обучения, предложеных Г.А.Ковалевым.
Весомый вклад внесла Л.А.Петровская в разработку практических процедур тренинговой работы. Ею предложена система правил организации эффективной обратной связи.

Анализируя

различные психотерапевтические системы, В.В.Столин, В.Ю.Большаков подчеркивают, что в основе успеха групповой психотерапии лежит способность к актуальной самоперестройке [7].

Методологическим принципом построения тренинга является принцип деятельностного подхода.

Тренинг состоит из различных методов психологического воздействия. Каждый метод имеет свои специфические механизмы коррекционного действия, где «вместе с тем существует основной рычаг, который объединяет все по-разному организованные приемы воздействия: главным является реализация индивидуального подхода. Важно создать условия для личностного роста.

Тренинг планирует не достижения результата, а создает условия для роста личности. Поэтому используются естественные движущие силы личностного развития: деятельность и система его отношений, которые являются лично значимыми, индивидуально ярко окрашены, имеют острые эмоционально насыщенные переживания.

В эмоционально насыщенные моменты и происходит коррекция: переворот в сознании, распределение и перестройка элементов сознания и самосознания - это результат острых переживаний.

Достижение нового взгляда, нового сознания - это и есть основа творческого подхода в тренинге. Важным в тренинге является и язык невербальной коммуникации, и искренность переживаний. $\mathrm{B}$ наибольшей степени необходимы педагогам тренинги саморегуляции эмоциональной сенситивности. Причина тому особенности профессии: постоянно высокий уровень самоконтроля, активное взаимодействие с детьми, оценочная деятельность, эмоциональное общение с воспитанниками. Все перечисленные факторы приводят к повышенным нервным перегрузкам, эмоциональному выгоранию педагогов, нарушению взаимоотношений с учащимися, снижению эффективности познавательной активности школьников. Предлагаемый вариант тренинга развития эмоциональной сенситивности учителей является составной частью комплексной методики коррекции эмоционального состояния учителей и тренинга сенситивности, разработанного Г.Смитом.

Термин тренинг сенситивности (ТC) используется достаточно широко и может обозначать разнообразные виды группового тренинга. Так, Рудестам (Rudestam K., 


\begin{tabular}{|c|c|c|c|c|c|c|}
\hline \multirow{4}{*}{ Impact Factor: } & ISRA (India) & $=3.117$ & SIS (USA) & $=0.912$ & ICV (Poland) & $=6.630$ \\
\hline & ISI (Dubai, UAE & $=0.829$ & РИНЦ (Russia) & $=0.156$ & PIF (India) & $=1.940$ \\
\hline & GIF (Australia) & $=0.564$ & ESJI (KZ) & $=8.716$ & IBI (India) & $=4.260$ \\
\hline & JIF & $=1.500$ & SJIF (Morocco & $=5.667$ & OAJI (USA) & $=0.350$ \\
\hline
\end{tabular}

1982) рассматривает ТС как разновидность $\mathrm{T}$ групп, имеющую своей целью общее развитие индивида посредством выявления жизненных ценностей человека и усиление чувства само идентичности. С точки зрения Рудестама, Т группы различаются между собой по целевому назначению: одни из них ориентированы на развитие умений, способствующих повышению эффективности организационной деятельности, другие - на формирование межличностных отношений и изучение процессов, происходящих в малых группах. Для групп сенситивности улучшение группового функционирования и развитие личностных умений являются вторичными по отношению к общему развитию личности. Однако и в таком коллективе сохраняется контекст понимания группового процесса, что является отличительной чертой всех типов Тгрупп. Роджерс (Rogers C. R.) считал термин Т. C. более общим по отношению к термину “Т группы”. Выделяя две основные формы групповой работы (Т. С. и группы организационного развития), он относил к Т. С. Т группы и группы встреч. Некоторые авторы относят к Т. С. также и так называемые группы организационного развития, отмечая при этом, что группы могут различаться в зависимости от того, что является целью работы и находится в центре внимания - организационные структуры или индивидуальное развитие. В рамках такого подхода Т. С. может быть ориентирован, например, на конфликты между служащими и руководителями, на поиск путей их разрешения для снижения напряжения и отчужденности и повышения продуктивности совместного труда. В таких группах целью является тренинг эффективной групповой деятельности в противоположность авторитарному управлению, a также замена фасадного ролевого поведения открытостью и искренностью. В качестве основной задачи Т. С. большинство авторов рассматривает совершенствование способности человека понимать других людей.

Л. А. Петровская (1982), анализируя зарубежную литературу[8] , указывает, что обычно выделяют два уровня целей: непосредственные и метацели, или цели более высокого уровня. К последним относят: 1) формирование у индивида духа исследования, готовности экспериментировать со своей ролью; 2) развитие аутентичности в межличностных отношениях; 3) расширение межличностного сознания (т. е. знания о других людях); 4) выработка способности вести себя с окружающими в сотрудничающей, а не авторитарной манере и пр. К непосредственным целям относят: рост самосознания участников, связанный с получением сведений о том, как другие воспринимают поведение каждого; обострение чувствительности к групповому процессу, поведению других, связанное прежде всего с восприятием более полного ряда коммуникативных стимулов, получаемых от других (обычно, формулируя эту цель, используют понятие эмпатии): понимание условий, которые затрудняют или облегчают функционирование группы; развитие диагностических учений в межличностной сфере; развитие умений успешно вмешиваться во внутригрупповые и межгрупповые ситуации; обучение тому, как учиться.

Ю. $\mathrm{H}$.

Емельянов (1985) выделяет следующие задачи Т. C.: 1) повышение уровня самопонимания и понимания других; 2) чувственное понимание групповых процессов, познание локальной структуры; 3) развитие ряда поведенческих навыков. Иногда в качестве основной цели выделяют обучение и тренинг возможностей, усиливающих социальную компетенцию. В самом общем виде цели Т. С. могут быть определены как обострение чувствительности к групповым процессам, к собственной личности и другим людям. Повышение восприимчивости к групповым процессам, к собственной внутренней жизни и внутренней жизни других людей, к своим и чужим ролям, позициям и установкам, воспитание открытости, искренности и спонтанности осуществляется при Т. С. за счет использования межличностного взаимодействия и межличностных взаимоотношений, анализа группового процесса, таких феноменов, как групповые цели и нормы, роли, групповая структура, проблемы руководства и лидерства, групповые конфликты и групповое напряжение и т. д. В этом отношении Т. С. имеет много общего с групповой психотерапией, однако, в отличие от нее, практически полностью ориентирован на ситуацию “здесь и теперь”, исследование группового процесса, того, как человек действует в коллективе, в чем состоит его влияние на других и как можно улучшить то, что он делает. Т. С. находит широкое применение в подготовке специалистов в области школьных психологов и педагогов средней школы и вузов. Использование этой формы тренинга позволяет развивать у будущих психологов и педагогов чувствительность к групповому процессу, способность к его более адекватному пониманию и использованию в ходе групповой психотерапии, умение оценивать отношения, установки, психологические проблемы и внутренние конфликты людей на основании анализа межличностного взаимодействия, a также способствует углубленному пониманию собственной личности, собственных установок, позиций, отношений, потребностей и мотивации. При подготовке учителей и школьных психологов T. С. может быть направлен как на решение 


\begin{tabular}{|c|c|c|c|c|c|c|}
\hline \multirow{4}{*}{ Impact Factor: } & ISRA (India) & $=3.117$ & SIS (USA) & $=0.912$ & ICV (Poland) & $=6.630$ \\
\hline & ISI (Dubai, UAE & $=0.829$ & РИНЦ (Russia) & $=0.156$ & PIF (India) & $=1.940$ \\
\hline & GIF (Australia) & $=0.564$ & ESJI (KZ) & $=8.716$ & IBI (India) & $=4.260$ \\
\hline & JIF & $=1.500$ & SJIF (Morocco & $=5.667$ & OAJI (USA) & $=0.350$ \\
\hline
\end{tabular}

отдельных задач (например, только на повышение чувствительности к групповым процессам или на становление более глубокого и адекватного самопонимания), так и на реализацию в процессе занятий более широких возможностей, предоставляемых данной формой тренинга. Главным явилось реализация индивидуального подхода, создание условий для личностного развития - деятельность и система его отношений. Именно поэтому мы старались в любом приеме создавать условия для деятельности и воспроизведения системы отношений, которые являются лично значимыми и индивидуально окрашенными, имеют острые эмоциональные переживания.

Использование технологических приемов сенситивности позволяет, ан наш взгляд, актуализировать основные сферы психической жизни учителя: когнитивную, аффективную, поведенческую.

\section{Conclusion}

Технологические приемы, позволяющие учителю глубже познавать и понимать ребенка и самого себя, актуализируют в большей степени когнитивную сферу личности учителя и развивают у него педагогическую направленность на ребенка, любовь к нему [9]. Применение «эмоционально сенситивных технологий» актуализирует аффективную сферу личности учителя и, таким образом, изменяет, расширяет, углубляет систему отношений «учитель ученик». Обработка приемов вербального и невербального поведения (постановка позы, жеста, походки, интонации, «постановка» улыбки и т.д.) актуализирует поведенческую сферу учителя и оптимизирует его на предупреждение изменения эмоционального настроения учеников, тем самым адекватно воздействовать на ситуацию, создаваемую в процессе взаимообщения [10]. Отношения между участниками должны быть доброжелательными: это и результат, и условие успешной работы. От психологического комфорта и раскрепощенности участников зависит их активность, глубина эмоциональной включенности, готовность поделиться своим опытом. Участие в тренинге создает у участников определенную готовность к дальнейшему саморазвитию и обучению приемам регулирования своего эмоционально сенситивного состояния.

Цель тренинга состоит в развитии у педагогов установки на взаимопонимание, обучение приемам регулирования своего эмоционально - сенситивного состояния, овладение способами саморегуляции, самообладания, рациональных способов общения. Актуализация и соотнесение предстоящей совместной деятельности участников тренинга, выявление ожиданий, а также формирование способностей саморазвития, механизмов устойчивости.

В ходе решаются следующие задачи:

1.Формирование представлений о значении управления эмоционально - сенситивным состоянием в педагогической деятельности и общении;

2.Развитие

психологической наблюдательности как способности фиксировать и запоминать всю совокупность сигналов, получаемых от другого человека или группы.

3.Осознание и преодоление интерпретированных ограничений, накладываемых теоретическими знаниями и стереотипизированными фрагментами сознания.

4.Формирование и развитие способности прогнозировать поведение другого, предвидеть свое воздействие на него.

5. Осознание педагогами собственных социально - психологических возможностей достижения взаимопонимания, установок

6. Распознание и идентификация собственных негативных эмоциональных состояний, возникающих при общении с детьми, ориентированными на сотрудничество.

\section{References:}

1. Isaev, D. I. (1983). Ohrana psihicheskogo zdorov'ya detej $i$ profilaktika. Psihogigiena i psihoprofilaktika / Sb. Nauchnyh trudov. NII im. V.M.Bekhtereva. (pp.8-13). Leningrad.

2. Gul'chevskaya, N. E. (2003). Sistemnyj analiz professional'nyh situacij, vyzyvayushchih trevozhnost' uchitelya. Materialy 5 vserossijskoj konferencii «Psihologiya i psihoterapiya. Trevoga i strah: edinstvo i mnogoobrazie vzglyadov» (809 fevralya). (pp.35-36). Spb.: Izd-vo SpbGU.

3. Myager, V. K. (1983). Aktual'nye problemy psihogigieny i psihoprofilaktiki. Sb. Nauchnyh trudov. NII im. V.M.Bekhtereva. (pp.13-17). Leningrad.

4. Glotochkin, A. D. (1993). O psihologicheskoj pomoshchi uchashchimsya kak vazhnejshij funkcii uchitelya. Psihologo - pedagogicheskaya 


\begin{tabular}{|c|c|c|c|c|c|c|}
\hline \multirow{4}{*}{ Impact Factor: } & ISRA (India) & $=\mathbf{3 . 1 1 7}$ & SIS (USA) & $=0.912$ & ICV (Poland) & $=6.630$ \\
\hline & ISI (Dubai, UAE & $=0.829$ & РИНЦ (Russia & $=0.156$ & PIF (India) & $=1.940$ \\
\hline & GIF (Australia) & $=0.564$ & ESJI (KZ) & $=8.716$ & IBI (India) & $=4.260$ \\
\hline & JIF & $=1.500$ & SJIF (Morocco & $=5.667$ & OAJI (USA) & $=0.350$ \\
\hline
\end{tabular}

korrekciya i psihoterapiya deviantnogo povedeniya i disgarmonii $\mathrm{v}$ razvitii lichnosti detej i podrostkov. (Tezisy dokladov Mezhdunarodnoj nauchno - prakticheskoj konferencii. Voronezh, 13-17 sentyabrya). (pp.8-9). Voronezh: Izd-vo Voronezhskogo pedinstituta.

5. Sonin, V. A. (1998). psiholog-pedagogicheskij analiz professional'nogo mentaliteta uchitelya. Avtoreferat na soiskanie uch. st. d. ps. Nauk. (p.49). Moscow.

6. Aronson, E., Wilson, T. D., \& Akert, R. M. (2002). Social'naya psihologiya. Psihologicheskie zakony povedeniya cheloveka v sociume. (p.445). Spb.: PRAJM - EVROZNAK.

7. Berns, R. (1986). Razvitie YA-koncepcii $i$ vospitanie. (p.420). Moscow: Progress.
8. Madanievoj, Z. B. (2002). Psihologicheskie osnovy upravleniya ehmocional'nym sostoyaniem uchitelya. (p.25). Almaty.

9. Punch, K. F. (1992). Psychological distress in secondary teachers research findings and their inmplications. J.Educ. admin., 301 №1, 42-54.

10. Temina, S. Y. (2002). Konflikty shkoly ili shkola konfliktov»? (Vvedenie v konfliktologiyu obrazovaniya). (p.144). Moscow: MPST; Voronezh: Izd-vo NPO «MODEHK».

11. (1997). Faktory riska psihicheskoj dezadaptacii $u$ pedagogov masovyh shkol. Posobie dlya vrachej i psihologov / Pod. Red. L.I.Vassermana, M.A.Berebina (Eds.). (p.52). Spb. 